\title{
VASCULARITY AND ANGIOGENESIS LEVEL CORRELATIONS WITH THE CLINICAL BEHAVIOR OF THE CENTRAL AND PERIPHERAL GIANT CELL GRANULOMAS OF THE ORAL CAVITY
}

\author{
Samah I. Mourad*, Sally Awad* and Ali Shamaa**
}

\begin{abstract}
Purpose: The aim of the current study was to compare vascularity and angiogenic activity in peripheral and central giant cell granulomas (GCGs) of the jaws as reflected by vascular endothelial growth factor (VEGF). Patients and Method: 3 males and 7 females complaining of peripheral giant cell granuloma (PGCGs) and fifteen (5 males \& ten females) with central giant cell granuloma (CGCGs) were selected to assess and compare the VEGF immunoexpression in multinucleated giantcells, and mononuclear surrounding stroma. Results: The expression levels of VEGF were greater in CGCGs compared to PGCGs and in aggressive CGCG more than nonaggressive. Conclusion: The vascularity and level of angiogenesis within aggressive CGCGs are higher than those in non-aggressive lesions. The stronger VEGF expression, the higher clinical behavior aggressiveness of the different giant cells granuloma lesions.
\end{abstract}

KEY WORDS: Angiogenesis, Giant cell Granuloma, Oral, VEGF.

\section{INTRODUCTION}

Central giant cell lesion (CGCL) and peripheral giant cell lesion (PGCL) are widely considered proliferative non-neoplastic processes that occur in the jaws ${ }^{1}$. Giant cell granulomas may occur on the gingival or edentulous alveolar process as PGCG or within the bone as $\mathrm{CGCG}^{2}$. PGCL is an infrequent exophytic reactive process arises because of local irritating factors and CGCL is an intra-bony lesion with no clear evident etiology ${ }^{1}$.
The PGCG is an exophytic lesion of the oral cavity. It is the most frequent giant cell lesions of the jaws ${ }^{3}$. The clinical appearance is similar to pyogenic granuloma, that is, a fleshy, soft, sessile nodular or pedunculated, frequently with an ulcerated surface and with a red, brown, or bluish hue. The margins of the edentulous alveolar ridge and the gums region are its common location, with more frequent observation in the posterior area of the lower jaw ${ }^{4}$. Bleeding tendency and erosion of the

\footnotetext{
* Associate Professor, Department of Oral and Maxillofacial Surgery, Faculty of Dentistry, Mansoura University, Mansoura, Egypt.

** Professor, Department of Oral Biology, Faculty of Dentistry, Minia University, Egypt.
} 
underlying alveolar bone can occur with peripheral giant cell lesions ${ }^{5}$. It is more common in the $5^{\text {th }}$ and $6^{\text {th }}$ decades of life with a slight female predilection ${ }^{4}$.

Central giant cell granuloma (CGCG) is an uncommon non-odontogenic benign intraosseous lesion with uncertain etiology. It accounts for nearly $10 \%$ of all jaws benign lesions. Up to $60 \%$ of all Lesions occur in young children about 2 years old and earlier than third decade of life. It affects women more often than men ${ }^{6}$.

CGCG occurs almost exclusively in the jaws and it has variable clinical behavior and is difficult to predict ${ }^{6}$. Eventually, it may become aggressive leading to the expansion and perforation of cortex resulting into mobility and displacement of teeth with root resorption. The nonaggressive variant is usually exhibit slow growth with asymptomatic lesions, and minimal proportion to recur. Currently, there are no reliable histologic methods or molecular techniques in order to differentiate between aggressive and nonaggressive giant cell lesions ${ }^{7}$.

The radiographic appearance of CGCG is not pathognomic and may be confused with other lesions, such as ameloblastoma, odontogenic keratocyst, aneurysmal bone cyst and hyperparathyroidism ${ }^{2}$. The treatment of choice for CGCG is local curettage. However, aggressive CGCG may recur which may necessitate extensive bone surgery resulting in jaw defects ${ }^{8}$.

Both lesions (CGCG and PGCG) exhibit the same microscopic features showing abundant mononuclear cells, admixed with abundant multinucleated giant cells (GC) present in a cellular fibrous stroma usually exist near to the wall of blood vessels. Multiple Foci of hemorrhage with hemosiderin deposition, and blood-filled pools ${ }^{9}$. In spite of their similarity, CGCG and PGCG have distinct clinical behavior ${ }^{1,4}$. Various jaws entities can have the same histologic features, including hyperparathyroidism, cherubism, and the central GC granuloma ${ }^{7}$. Furthermore, the histogenesis of the oral cavity giant cell lesions remains arguable, as assessment is still a matter of debate about the feasibility that it is the representative of a reactive, an inflammatory, an infective, or a neoplastic process. The other assumption is the vascular hypothesis evoked that CGCG belongs to the primary vascular proliferative mesenchymal jaw lesions ${ }^{10,11}$.

Angiogenesis is the generation of new blood capillaries from pre-existing blood vessels. It exists physiologically as in embryologic development and wound healing as well as in other pathologic conditions such as tumor growth facilitation ${ }^{7}$. It has been exhibited that numerous neoplastic and non-neoplastic diseases biologic behavior would be affected by the angiogenesis process ${ }^{12}$. This phenomenon is regulated by several growth factors and cytokines. The utmost efficient inducers of angiogenesis are the Vascular endothelial growth factor (VEGF) and basic fibroblast growth factor (bFGF) and they also have a synergistic infeleunce ${ }^{13}$. VEGF, a soluble molecule that directs the vascular development, acts as a substantially specific mitogen for endothelial vascular cells, significantly induces vascular permeability and serves as a survival factor for new blood vessels formation. It is produced and released from activated monocytes and macrophages. Recently, the major source of VEGF has been exhibited to be the vascular endothelial cells ${ }^{14,15}$. VEGF is a potent angiogenic factor that has been contributory in the solid tumors progression. Besides its part in angiogenesis, studies have stressed VEGF importance in osteoclastogenesis where it serves as a powerful agent for pre-osteoclasts chemo-attraction ${ }^{16,17}$.

The varying clinical behavior and histological parametershaveattractedinterest of many researchers to understand this diverse group of lesions, in order to predict clinical behavior, prognosis of giant cell lesions and to provide appropriate treatment $2,4,12$. Therefore, the aim of the study is to evaluate vascularity and angiogenic activity in peripheral and central giant cell granulomas (GCGs) of the jaws as reflected by VEGF. 


\section{PATIENTS AND METHODS}

\section{1-Patients}

The present study was conducted in the period from January 2018 to March 2019 and included twenty-five patients ( 8 males and 17 females) that were selected from the outpatient clinic of the Oral and Maxillofacial Surgery Department, Faculty of Dentistry, Mansoura University. The patients involved in this study complaining from giant cell granulomas.

The patient's details and complete clinical evaluation regarding age, gender, size and location of lesions, presence or absence of pain, swelling, rate of growth, regional lymphadenopathy, recurrence if found along the follow up period (one year), and radiographic evaluation (root resorption, cortical thinning, perforation) were recorded in (table1).

According to the clinical presentation and radiographic appearance, these 25 patients were categorized into:

Group 1: Peripheral lesions (ten cases) (Fig1a,b)

Group $2 *$ Bony lesions:
Two sub groups were defined from the bony lesions ${ }^{7}$ :

Subgroup I: Non-aggressive Lesions (8 Cases) Characterized by:

1) size less than $5 \mathrm{~cm}, 2)$ Slow growth, 3) The absence of root resorption, 4) no tooth displacement, 5) The absence of cortical perforation, 6) No recurrences.

Subgroup II: Aggressive Lesions (7 Cases)

Characterized by: 1) lesion size $\geq 5 \mathrm{~cm} \mathrm{2)}$ Rapid growth, 3) Root resorption, 4) tooth displacement, 5) Cortical perforation, and 6) Recurrences (Recurrence of these lesions was ranging from 2-9months).

2- Hematological Analysis included serum calcium and phosphorus level together with hormonal essay for the parathyroid hormone to exclude brown tumor of hyperparathyroidism were done. GCLs from patients with cherubism, hyperparathyroidism, and Noonan's syndrome were excluded ${ }^{7}$. Preceding the biopsy procedure time, no previous therapeutic treatment had been received for any patients. All patients' undergone surgical excision of their lesions under local anesthesia (Fig 2 a, b, c).

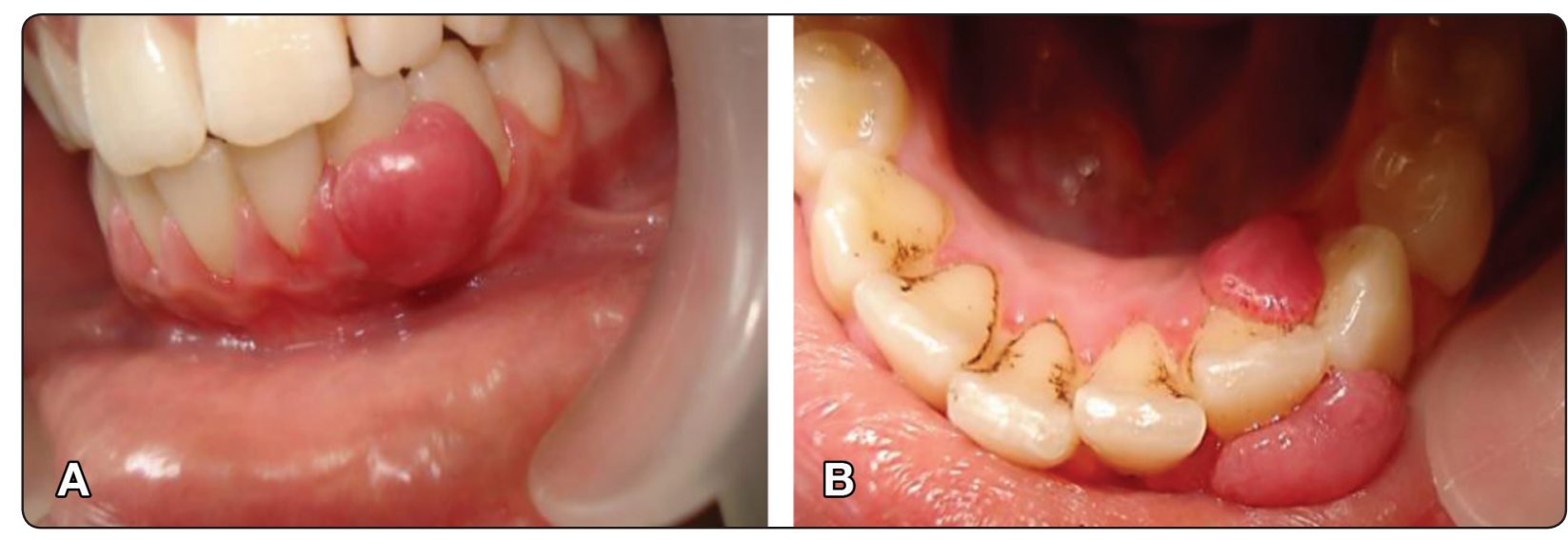

Fig. (1) Pedunculated, solitary, exfoliated, lesion in the gingiva between the lower right lateral incisor and canine that extend both (a) bucally and (b) ligually 

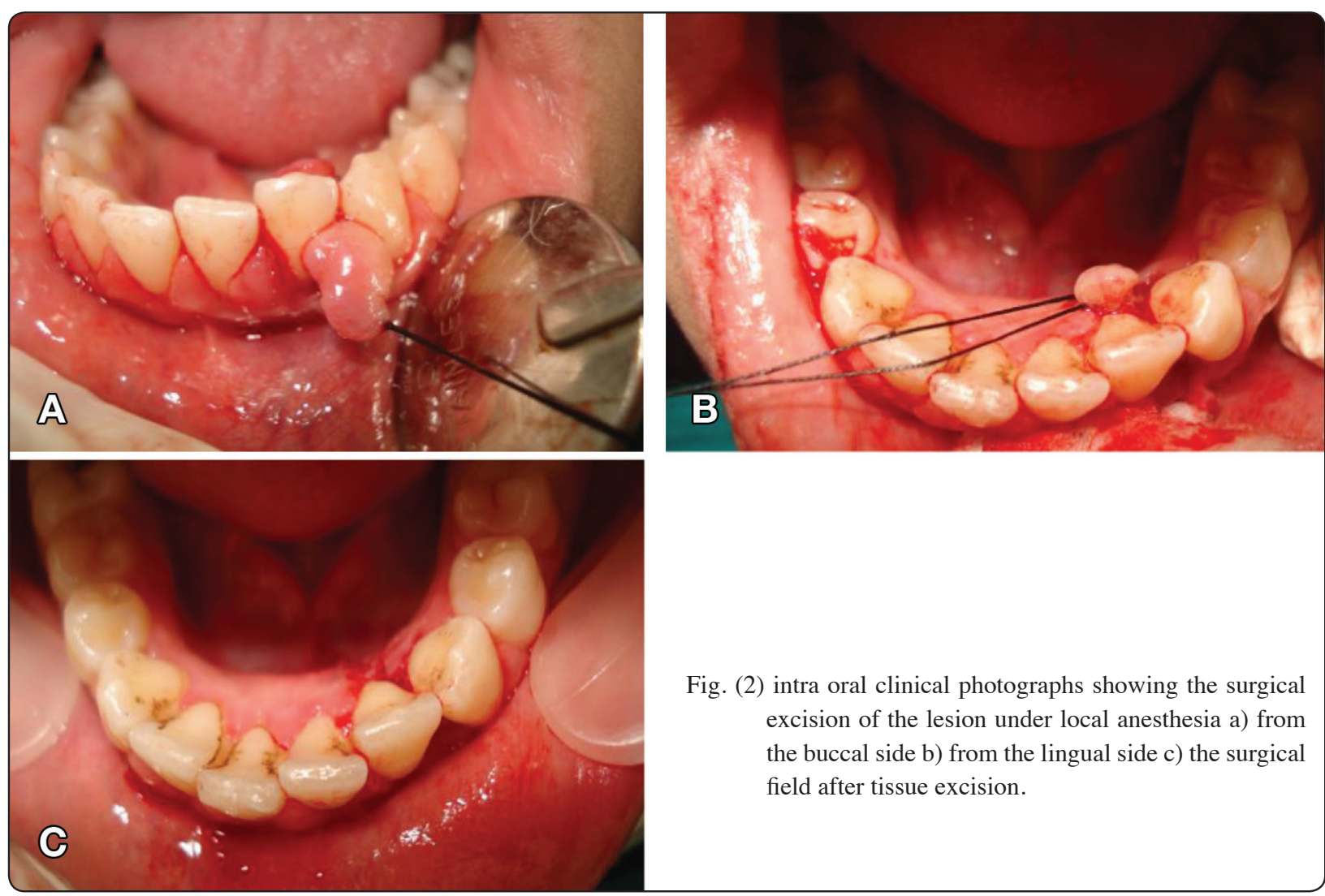

Fig. (2) intra oral clinical photographs showing the surgical excision of the lesion under local anesthesia a) from the buccal side b) from the lingual side $c$ ) the surgical field after tissue excision.

Biopsy specimens (Fig 3) were paraffin embedded after fixation with neutral buffered formalin solution $10 \%$. From each paraffin block, four-micron thickness serial sections were obtained, and then mounted on coated slides and dried for staining.

\section{3- Staining}

\section{I - Hematoxylin and eosin staining sections:}

This was performed for the evaluation of the studied cases to confirm diagnoses (Fig 4) and to classify the studied cases into the required groups according to their degree of aggressiveness

\section{II- Immunohistochemical staining:}

\section{Procedure}

For the immunohistochemistry, the 4-micron thickness sections were deparaffinized and immersed in $3 \%$ hydrogen peroxide to block endogenous

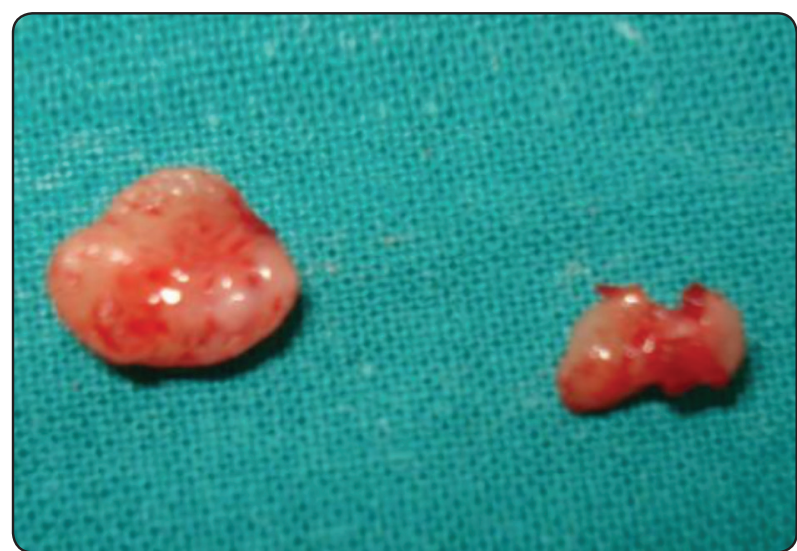

Fig. (3) The excised tissue (biopsy) that was sent for histopathological examination.

peroxidase activity. Phosphate-buffered saline (PBS) were used for washing the sections. Immersion of the slides in deionized water and followed by PBS rinsing. Exposure to Tris (hydroxymethyl) aminomethane/ethylenediaminetetraacetic acid (Dako, Carpinteria, CA) was done at pH 9.0 with 
microwaving prior to VEGF staining. Incubation of the sections at the room temperature for 60 minutes with the primary antibody VEGF-rabbit monoclonal anti-VEGF (Labvision, Fremont, CA) diluted to 1:25 in PBS was performed. Then slides were washed twice in PBS, and incubated with a biotinylated secondary antibody (Envision Plus; Dako), followed by 2 PBS rinses, then preformed avidin- biotin complex (Dako) was applied for half an hour ${ }^{7}$.

\section{Evaluation: quantification of $V E G F$-positive $G C$}

In the whole section, VEGF-positive percentage in the giant cells was calculated from the total number of the respective cell type at $\mathrm{x} 100$ magnification. As GC showed a wide percentage of positively stained cells, lesions were categorized according to VEGF-positive GC percentage into two groups: 1) high immunoreactivity (more than or equal 50\% staining) and 2) low immunoreactivity (less than $50 \%$ staining) ${ }^{7}$.

\section{Statistical analysis}

Statistical analysis of the data was done by using the computer program Statistical package for social science (SPSS version 17). The quantitive data were presented in the form of mean and standard deviation. Student's t test was used as a test of significance to compare between the two groups. Significance was considered when $\mathrm{P}$ value less than 0.05 .

\section{RESULTS}

The current study composed of 25 patients with PGCG and CGCG. The patient's ages in this study ranged from (11:55) years with a mean of $(33.12 \pm 11.6$ years). Females were more frequently affected than males (17 females (68\%: 8 males $32 \%$ ) with statistically significant correlations were found between gender $(\mathrm{p}=0.05)$. The mandible was affected more than maxilla (21 mandible $84 \%$ :
4 maxilla 16\%) and the anterior regions of the jaws were observed to be the most affected areas (16 anteriorly 64\%). (Table 1).

PGCGs samples collected from 10 cases (40\%). 3 samples (30\%) occurred in males and $7(70 \%)$ in females $(\mathrm{p}=0.045)$. Of these, 6 were found in the mandible (60\%) and $4(40 \%)$ in the maxilla (3 in ant. maxilla $30 \%$ : 1 in post. maxilla $10 \%$ ). The youngest patient was 11-year-old boy with a lesion on the right anterior mandibular gingiva while the oldest patient was 55- years old female with a maxillary PGCG on the gingiva of the anterior region. There was an increased intensity/staining of VEGF in the peripheral areas of the PGCG samples.

The number of CGCGs samples were 15, which occurred in 5 males (33.3\%) and 10 females (66.7\%). All cases were found in the mandible (10 in anterior mandible 66,7\%: 3 in mandibular body 20\%: 2 in mandibular body and ramus $13.3 \%$ ). A 16-year-old girl with a lesion in right mandibular body, and a 49-year-old woman with a lesion in the right canine area constituted the youngest and oldest patients with CGCG. The mean ages for individuals with PGCG were 34.2 \pm 13.2 years and for CGCG were $32.4 \pm 10.8$ years, respectively (Table 1 ). Median ages (34 years) were used as the cut-off point to divide patients into younger and older groups as proposed previously ${ }^{18}$.

The CGCGs were aggressive in 7 patients (46.7\%) that occurred in 2 males $(28.57 \%)$ and 5 females $(71.43 \%)(\mathrm{p}=0.803)$. The non-aggressive in $8(53.3 \%)$ which occurred in 3 males $(37.5 \%)$ and 5 females $(62.5 \%) \quad(\mathrm{p}=0.12)$. All the 15 specimens represented VEGF immunoreactivity. VEGF Immunohistochemical staining showing high staining $(>50 \%)$ of GCs and stroma within aggressive CGCG (Fig5). High reactivity within the multinucleated GCGs was found in 4 of 7 (57.14\%) aggressive lesions as shown in (Fig 6) compared with 1 of $8(12.5 \%)$ non-aggressive lesions. 
TABLE (1) Comparison of the study population in relation to the demographic data and clinical parameters

\begin{tabular}{|c|c|c|c|}
\hline Parameters & CGCG & CGCG & PGCG \\
\hline & Non-aggressive lesions & Aggressive lesions & \\
\hline & 8 Cases & 7 Cases & 10 Cases \\
\hline \multicolumn{4}{|l|}{ Gender } \\
\hline Male & $3(37.5 \%)$ & $2(28.6 \%)$ & $3(30 \%)$ \\
\hline Female & $5(62.5 \%)$ & $5(71.4 \%)$ & $7(70 \%)$ \\
\hline P-value & 0.12 & 0.803 & 0.045 \\
\hline \multicolumn{4}{|l|}{ Age } \\
\hline$\leq 34$ years & 5 & 3 & 5 \\
\hline$>34$ years & 3 & 4 & 5 \\
\hline Mean \pm SD & $30.25 \pm 10.3$ & $34.86 \pm 11.6$ & $34.2 \pm 13.2$ \\
\hline \multicolumn{4}{|l|}{ Size } \\
\hline$\leq 2 \mathrm{~cm}$ & 0 & 0 & 8 \\
\hline$>2 \mathrm{~cm}$ & 0 & 0 & 2 \\
\hline$\leq 5 \mathrm{~cm}$ & 8 & 0 & 0 \\
\hline$>5 \mathrm{~cm}$ & 0 & 7 & 0 \\
\hline \multicolumn{4}{|l|}{ Location } \\
\hline Mandible, anterior & $7(87.5 \%)$ & $3(42.9 \%)$ & $3(30 \%)$ \\
\hline Mandible, posterior & 0 & 0 & $3(30 \%)$ \\
\hline Mandible, body, and ramus & $1(12.5 \%)$ & $4(57.1 \%)$ & 0 \\
\hline Maxilla, anterior & 0 & 0 & $3(30 \%)$ \\
\hline Maxilla, posterior & 0 & 0 & $1(10 \%)$ \\
\hline \multicolumn{4}{|l|}{ Rate of growth } \\
\hline Slow & 8 & 2 & \\
\hline Rapid & 0 & 5 & \\
\hline Swelling & 6 & 7 & \\
\hline Root resorption & $\mathrm{N}$ & 4 & \\
\hline Cortical thinning & $\mathrm{N}$ & 5 & \\
\hline Recurrence & $\mathrm{N}$ & 3 & \\
\hline
\end{tabular}

CGCG: central giant cell granuloma

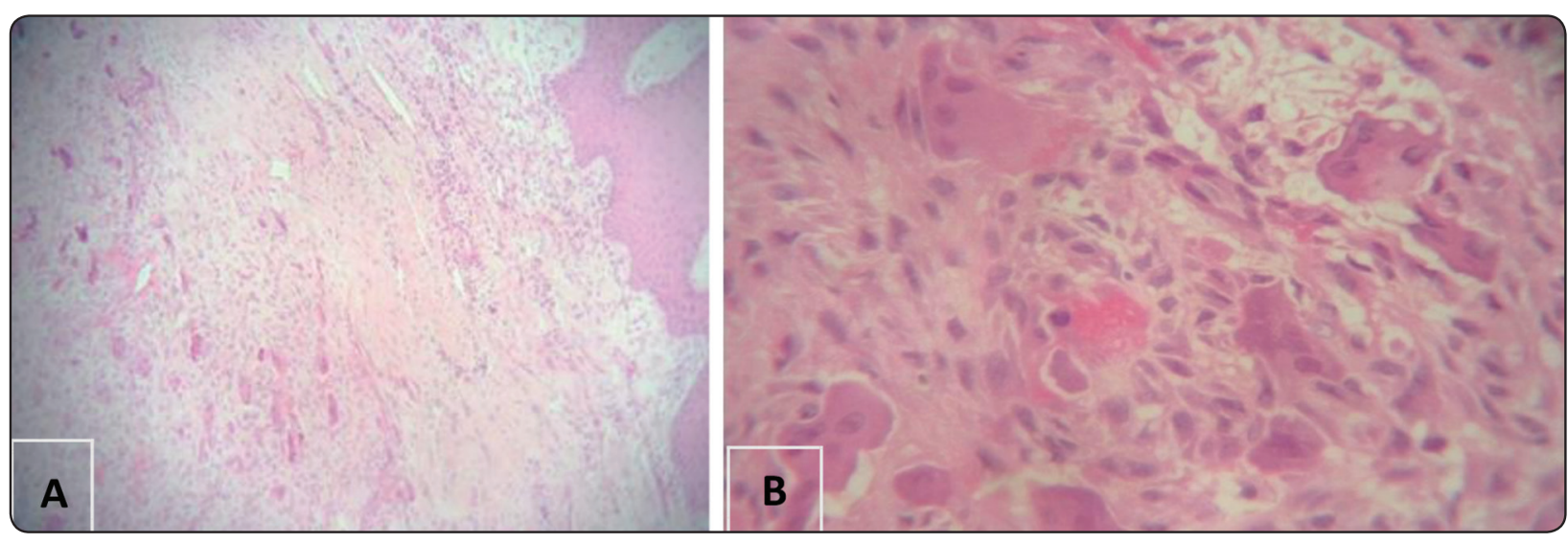

Fig. (4) A, Photomicrograph of histopathological examination showing H\&E staining of PGCG with focal distribution of multinucleated giant cells. (100X) B, Photomicrograph Showing H\&E staining of GCs and stroma within CGCG. (200X) 


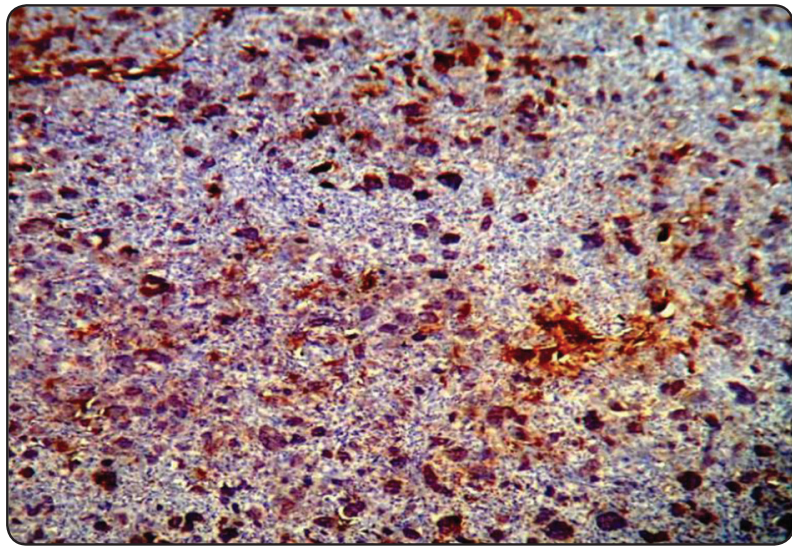

Fig. (5) Photomicrograph of VEGF Immunohistochemical staining showing high staining $(>50 \%)$ of GCs and stroma within aggressive CGCG. (X 40)

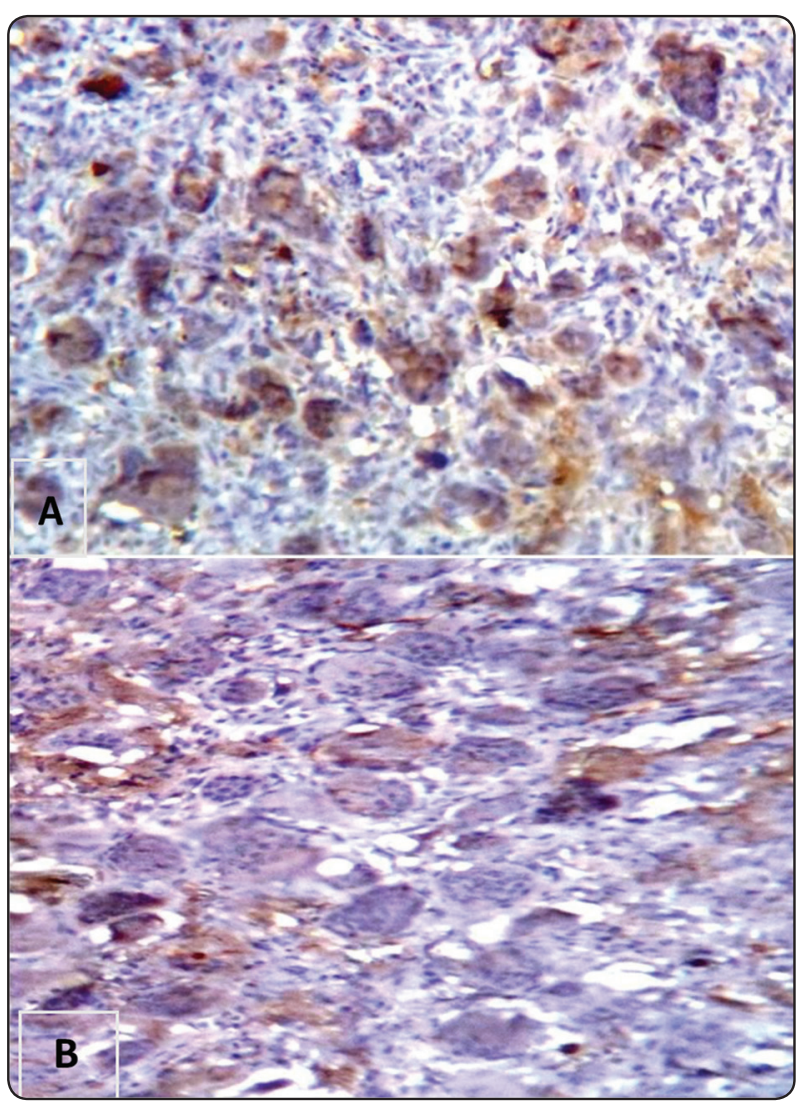

Fig. (6) Variable intensity of positive VEGF immunoreactivity in aggressive and nonaggressive CGCG cases. A, Photomicrograph showing high staining $(>50 \%)$ of GCs and stroma within aggressive CGCG. at $100 \mathrm{X}$ magnification. B, Photomicrograph showing low staining $(<50 \%)$ of GCs and stroma within nonaggressive CGCG at 100X magnification.

\section{DISCUSSION}

The subject PGCL and CGCL of the jaws is little understood and represent a matter of debate because the lesions may be confused and are not pathognomic both radiologically as well as histologically, with other jaws lesions ${ }^{1}$. Despite this, it is well known that they differ clinically in terms of their behavior. for providing appropriate treatment, the knowledge about their nature and origin is very crucial ${ }^{1,2,19}$. Moreover, the lesional vascular component characterization has not been fully investigated, thus in the present study we evaluated the vascularity and angiogenic activity in peripheral and central giant cell granulomas (GCGs) of the jaws using protein angiogenesis marker VEGF.

The demographic data analysis of this current study revealed the mean ages for Giant cell lesions is 33.12 (PGCG and CGCG are 34.2 and 32.4 respectively) these results were in accordance with other previous studies ${ }^{6,12,19}$. Female predilection in both lesions PGCG and CGCG was observed ( $\mathrm{p}$ $=0.05$ ) that showing similarity with other studies 5,6,12,19-21. PGCG occurs more commonly in females, a situation attributed by some authors that the more common female appearance of PGCG is associated to the role of particular ovarian sex hormones, that could be involved in its formation process ${ }^{5}$.

Regarding the location, PGCG has been reported in the literature to be more common in the mandible ${ }^{2,12}$, this result is corroborated with the current study $(60 \%$ mandible and $40 \%$ in the maxilla). Despite, Pen $\sim$ arrocha-Diago et $\mathrm{al}^{5}$ reported that the PGCG appears to exhibit a predilection for the maxilla molars and premolars regions, our results revealed that the anterior maxilla is the more common site (30\% anterior maxilla: $10 \%$ posterior maxilla).

Our finding also supports the rising body of the literature about the frequent location of the CGCGs anterior to the mandibular first molar and often cross 
the midline ${ }^{6,22,23}$. However, a recent review of 80 cases suggested that there is an equal predilection for the posterior mandible ${ }^{24}$.

Various markers have been used to assess the vascularity in giant cell granuloma and suggested the angiogenic activity of GCLs was proposed as a determinant of the aggressive nature of GCLs. Preceding angiogenesis analyses within GCLs have had contradictory results ${ }^{6,19}$. Vered et al. ${ }^{25}$ has demonstrated low mean microvascular volume of VEGF and b-FGF positive blood vessels in CGCG, and concluded that GCLs have minimal angiogenic activity; thus does not substantiate the CGCG installation as a true proliferative vascular lesion but no comparison was carried out between aggressive and nonaggressive lesions ${ }^{6,25}$. Moreover, Kashyap B et al ${ }^{2}$ has reported that no statistically significant difference was found in vascularity of CGCG, PGCG and GCT; thus, all the lesions were equally vascularity dependent. The recurrence rate of Giant cell lesions varies between $13-49 \%{ }^{26}$, with time interval time between diagnosis and the premier treatment and a recurrence treatment was 21 months ${ }^{27}$. The most common factors of increase the recurrence risk encompass the clinical activity of lesions, patients age, presence of cortical bone proliferation, and the size of the tumor 19,28, 29,30. Some studies revealed that the larger size of giant cells and their greater functional surface area may be correlated with tumors aggressive behavior ${ }^{19,31}$. Furthermore, Kruse-Loser et al., ${ }^{28}$ reported that the aggressive form of CGCG demonstrated greater number of giant cells, increased fractional surface area , and with high the mitotic activity.

On the other hand, Geschickter and Copeland ${ }^{32}$ concluded that although the multinucleated giant cells are prominently seen in CGCG or GCT, they are not considered as the primary proliferating tumor cells. It is hypothesized that the giant cells of CGCG arise are derived from a subset of mononuclear phagocytes. Differentiation of these precursor mononuclear cells into mature giant-cells was under the influence of some receptor activator, spindleshaped proliferating stromal cells (osteoblast-like) 6,32. According to $\mathrm{Sapp}^{33}$ these cells are slightly modified osteoclasts. Nevertheless, the prediction of CGCGs clinical behavior and recurrence from ultrastructural, and immunohistochemical evaluations is still uncertain ${ }^{19}$.

Our study observed increased levels of this protein in the multinucleated GCs and the surrounding stroma of aggressive lesions as compared with nonaggressive lesions. The results of this current study corroborate with the results of Peacock ZS et al ${ }^{7}$ and also substantiate the hypothesis that a proliferative vascular component within GCLs may be accountable for their clinical aggressiveness. Furthermore, these results advocate that the major role of VEGF in CGCL is related to the osteoclastogenesis process and, consequently, to stimulation of bone resorption. In congruent with this suggestion, the significant value of VEGF in chemotaxis and osteoclast formation was shown by several studies 12,17,34,35. Although PGCL may persuade the cortical bone resorption ${ }^{36}$, this process intensity is significantly lower in comparison to the CGCL observation results. This fact may clarify the lower expression of VEGF in the PGCLs that was in accordance to our observed results.

\section{CONCLUSIONS}

Finally, from our own results and previous data we can conclude that the greater VEGF expression in a giant cell lesion, the more aggressive biologic behavior is presented. The stronger immunostaining of this protein in multinucleated giant cells shows that these cells have greater metabolic activity and osteoclastogenesis, especially in aggressive CGCL. 


\section{REFRENCES}

1. Falci SG, Mesquita AT, Andrade BA, Miranda JL, Leon JE, Almeida OP, Santos CR. FASN expression angiogenesis and lymphangiogensis 1 in central and peripheral giant cell lesions. J Appl Oral Sci,2014;22(2):131-137.

2. Kashyap B, Reddy SP, Desai R, Puranik RS, Vanaki SS. Computer assisted histomorphologic comparision and the expression of AgNORs in the central and peripheral giant cell lesions of the oral cavity and giant cell tumor of the long bone. J Oral Maxillofac Pathol,2014;18(Suppl 1):S54-S59

3. Brodbeck WG, Anderson JM. Giant cell formation and function. Curr Opin Hematol. 2009; 16:53-7.

4. Vk V, Hallikeri K, Girish HC, Murgod S. Expression of CD34 and CD68 in peripheral giant cell granuloma and central giant cell granuloma: An immunohistochemical analysis. J Oral Maxillofac Pathol, 2014; 18(3): 341-348.

5. Pen arrocha-Diago MA, Cervera-Ballester J, MaestreFerrı 'n L, Pen arrocha-Oltra D. Peripheral giant cell granuloma associated with dental implants: Clinical case and literature review. Journal of Oral Implantology, 2012; XXXVIII (1),527-532.

6. Hongal BP, Joshi P, Kulkarni V, Baldawa P. Central giant cell granulomas of the jaws: A review of the literature with its emphasis on differential diagnosis on related lesions. Int J of Cont Dent and Med Rev,2015;1-4.

7. Peacock ZS, Jordan RCK, Schmidt BL. Giant Cell Lesions of the Jaws: Does the Level of Vascularity and Angiogenesis Correlate with Behavior? J Oral Maxillofac Surg,2012; 70:1860-1866.

8. Infante Cossío P, Martínez de Fuentes R, Carranza Carranza A, Torres Lagares D, Gutiérrez Pérez JL. Recurrent central giant cell granuloma in the mandible: Surgical treatment and dental implant restoration. Med Oral Patol Oral Cir Bucal 2007;12:E229-32.

9. Li B, Yu SF, Li TJ. Multinucleated giant cells in various forms of giant cell containing lesions of the jaws express features of osteoclasts. J Oral Pathol Med, 2003; 32:367-75.

10. Kaban LB, Troulis MJ, Ebb M et al. Antiangiogenic therapy with interferon alpha for giant cell lesions of the jaws. J Oral Maxillofac Surg, 2002; 60: 1103-1111

11. Collins A. Experience with anti-angiogenic therapy of giant cell granuloma of the facial bones. Ann R Australas Coll Dent Surg, 2000; 15: 170-5.
12. Sadri D, Shahsavari F, Hezarkhani M, Shafizadeh M. Expression of CD34 and CD31 in Central and Peripheral Giant Cell Granulomas. J Dent Shiraz Univ Med Sci, 2019; 20(1): 10-15

13. Seghezzi G, Patel S, Ren CJ. Gualandris A, Pintucci G, Robbins ES, Shapiro RL, Galloway AC, Rifkin DB, Mignatti P. Fibroblast growth factor-2 (FGF-2) induces vascular endothelial growth factor (VEGF) expression in the endothelial cells of forming capillaries: an autocrine mechanism contributing to angiogenesis. J Cell Biol, 1998; 141: 1659-73.

14. Ferrara N, Gerber H-P, Le Couter J. The biology of VEGF and its receptors. Nat Med, 2003; 9: 669-76.

15. Pakala $R$, Watanabe $T$, Benedict $C R$. Induction of endothelial proliferation by angiogenic factors released by activated monocytes. Cardiovasc Radiat Med, 2002; 3: 95-101.

16. Ferrara N. Vascular endothelial growth factor: basic science and clinical progress. Endocr Rev 2004; 25: 581-611.

17. Niida S, Kaku M, Amano H, et al. Vascular endothelial growth factor can substitute for macrophage colonystimulating factor in the support of osteoclastic bone resorption. J Exp Med 1999; 190: 293-298.

18. Chaparro-Avendaño AV, Berini-Aytés L, Gay-Escoda C. Peripheral giant cell granuloma. A report of five cases and review of the literature. Med Oral Patol Oral Cir Bucal, 2005; 10: 48-57.

19. Yadav S, Singh A, Kumar P, Tyagi S. Recurrent case of central giant cell granuloma with multiple soft tissue involvement. Natl J Maxillofac Surg, 2014; 5: 60-66

20. Grand E, Burgener E, Samson J, Lombardi T. Posttraumatic development of a peripheral giant cell granuloma in a child. Dent Traumatol,2008;24:124-126.

21. Sahingur SE, Cohen RE, Aguirre A. Esthetic management of peripheral giant cell granuloma. J Periodontol, 2004;75:487-492.

22. Neville BW, Damm DD, Allen CM and Bouquot JE. Text book of oral and maxillofacial pathology . Chapter XII : soft tissue tumors. 1995,W.B. Saunders Company. P:373.

23. Potter BJ and Tiner B.D. Central giant cell granuloma, report of a case. Oral Surg Oral Med Oral Pathol, 1993;75:286-289. 
24. Kaffe I, Ardekian L, Taicher S, Littner MM, Buchner A. Radiologic features of central giant cell granuloma of the jaws. Oral Surg Oral Med Oral Pathol Oral Radiol Endod, 1996;81:720-726.

25. Vered M, Buchner A, Dayan D. Giant cell granuloma of the jaw bones-a proliferative vascular lesion? Immunohistochemical study with vascular endothelial growth factor and basic fibroblast growth factor. J Oral Pathol Med, 2006;35:613-619.

26. de Lange J, van den Akker HP, Klip H. Incidence and disease-free survival after surgical therapy of central giant cell granulomas of the jaw in the Netherlands. Head Neck, 2004;26:792-5.

27. Whitaker SB, Waldron CA. Central giant cell lesions of the jaws: A clinical, radiologic, and histopathologic study. Oral Surg Oral Med Oral Pathol, 1993;75:199-208.

28. Kruse-Losler B, Diallo R, Gaertner C. Central giant cell granuloma of the jaws: A clinical, radiologic, and histopathologic study of 26 cases. Oral Surg Oral Med Oral Pathol Oral Radiol Endod,2006;101:346-54.

29. Minic A, Stajcic Z. Prognostic significance of cortical perforation in the recurrence of central giant cell granulomas of the jaws. J Craniomaxillofac Surg,1996;24:104-8.

30. Bataineh AB, Al-Khateeb T, Rawashdeh MA. The surgical treatment of central giant cell granuloma of the mandible. J Oral Maxillofac Surg. 2002;60:756-61.

31. Yamaguchi T, Dorfman HD. Giant cell reparative granuloma: A comparative clinicopathologic study of lesions in gnathic and extragnathic sites. Int J Surg Pathol. 2001;9:189-200.

32. Reichart PA, Philipsen HP. Odontogenic Tumors and Allied Lesions. London: Quintessence Publishing Co. Ltd.; 2004. p. 319-30.

33. Liu B, Yu SF, Li TJ. Multinucleated giant cells in various forms of giant cell containing lesions of the jaws express features of osteoclasts. J Oral Pathol Med 2003;32:367-75.

34. Matos FR, Nonaka CF, Miguel MC, Galvão HC, de Souza LB, Freitas Rde A. Immunoexpression of MMP-9, VEGF, and $\mathrm{vWF}$ in central and peripheral giant cell lesions of the jaws. J Oral Pathol Med, 2011; 40: 338-344.

35. Kahn A, Chaushu G, Ginene L, Vered M. Age and Expression of CD163 and Colony-Stimulating Factor 1 Receptor (CD115) Are Associated with the Biological Behavior of Central Giant Cell Granuloma. J Oral Maxillofac Surg, 2017; 75: 1414-1424.

36. Souza PE, Mesquita RA, Gomez RS. Evaluation of p53, PCNA, Ki-67, MDM2 and AgNOR in oral peripheral and central giant cell lesions. Oral Dis ,2000; 6: 35-39. 